\title{
AC 2007-1941: STUDY ABROAD AT VILLANOVA: ANALYSIS OF AN EVOLVING PROGRAM
}

\section{Andrea Welker, Villanova University}

Dr. Andrea Welker, PE is an associate professor in the Civil and Environmental Engineering Department at Villanova University. She is the Study Abroad Adviser for her department.

\section{Lance Kenney, Villanova University}

Mr. Lance Kenney is the Director of the Office of International Studies at Villanova University. 


\title{
Study Abroad at Villanova: Analysis of an Evolving Program
}

\begin{abstract}
One way to prepare students for life in a "flat world" is through study abroad experiences. The Civil and Environmental Engineering Department at Villanova offers students several ways to go abroad during their time in our department: one or two semesters at a university overseas, summer programs run by Villanova, and internships. Since the class of 2001, 35 civil engineering students have studied abroad either at a university or through a summer program run by Villanova. Civil engineers comprised $37 \%$ of the engineering students that studied abroad in that time period; however, typically civil engineers make up $22 \%$ of each graduating class. In addition, the numbers of students participating in such programs increases every year: in the class of 2001 just one student went abroad as compared to 12 in the class of 2007. This indicates that within our college, the civil engineers are eager to study abroad and that they are enabled to act on this desire. This paper will discuss what we have done to increase the number of students studying abroad and provide student perspectives on their experiences. We will also describe how we propose to assess the program systematically so that we may continually enhance the program.
\end{abstract}

Introduction

Both $\mathrm{ABET}^{1}$ and the National Academy of Engineering's "Engineer of 2020"2 report note the importance of having culturally aware, internationally employable engineers that can survive in what is described by Friedman ${ }^{3}$ as a "flat world." One way to achieve this goal is through study abroad experiences. Interest in study abroad for engineering students is increasing as witnessed by the papers presented at the last ASEE conference ${ }^{4,5}$.

Villanova University

Founded in 1842 by the friars of the Order of St. Augustine, Villanova is a comprehensive Roman Catholic institution that welcomes students of all faiths. The university is located approximately 10 miles west of Philadelphia in what is often referred to as "The Main Line". The University offers a wide variety of degree programs through four colleges: the College of Liberal Arts and Sciences, the School of Business, the College of Engineering, and the College of Nursing. Villanova's more than 6,000 undergraduates come from 49 states plus Puerto Rico, the District of Columbia, and the U.S. Virgin Islands, and 29 foreign countries.

Office of International Studies and Overseas Programs

The Office of International Studies and Overseas Programs (OIS) at Villanova University is just over 15 years old. The primary charge of OIS is to oversee all aspects of education abroad, facilitate student exchange, manage international summer programs, and act as a campus 
resource for all things international. OIS has grown from having just a director and full-time secretary in 2000 to five full-time staff in 2006. Student participation rates in study abroad have doubled in five years, and a third of the class of 2006 had studied abroad as part of their academic career (with a quarter having studied overseas for at least a semester). The number of summer programs has also doubled in that time, jumping from nine to 18 . These totals led to Villanova University this year being ranked fourth nationally by Open Doors ${ }^{6}$ in its category for overseas student totals. In 2001, Villanova (like many of its peer schools) adopted a home tuition policy. Under the home tuition policy, students participating in overseas education programs pay the standard Villanova tuition regardless of the overseas location. Students may apply their Villanova financial aid to study abroad, just as they do when studying on campus.

The Mission Statement of the OIS is as follows:

The Office of International Studies and Overseas Programs fulfills the Villanova University promise "to add its influence to the search for world peace and justice by means of its academic programs and the pastoral ministry it provides for the members of the community." In fulfilling this promise, the OIS views its mission as one that enhances and strengthens the University's commitment to diversity, intellectual growth, and a global perspective. Thus, the OIS is committed to ensuring that an international educational perspective is an integral part of a Villanova University education.

The OIS mission statement segues with the academic strategic plan of the university (synopsis can be found at http://www.vpaa.villanova.edu/academicstrategicplan/goals.pdf). Specifically, the mission of OIS advances two objectives of the Strategic Plan: to "[e]nrich student academic experiences by means of...International and multicultural perspectives" and to "[s]erve as an intellectual and cultural resource for the extended local community [by promoting] to the community academic, cultural, intellectual, and professional programs and service".

The guiding philosophy of the OIS always has been one of immersion. It is not enough for students merely to be in a foreign country, participating in what John Dewey derisively called the "spectator theory of knowledge." They must be engaged with the "Other," actively and experientially learning about the culture in which they are studying. The mission of the University, therefore, is an important advocacy and pedagogical tool for education abroad.

As an Augustinian university, Villanova frames its holistic educational goals around the writing and influence of St. Augustine of Hippo. The Augustinian tradition has a three-fold influence on the OIS. First, from a simple biographical standpoint, St. Augustine's life and philosophy were intimately linked with his overseas teaching and learning. Second, the Augustinian order that was founded in his name is also known for a tradition of international service and cultural immersion. Third, and most importantly, the writings of Augustine enable us to require the highest levels of immersion possible as the core principles of this office. Augustinian social thought is based on a broadened sense of community: in regards to overseas study, this means we absolutely prohibit island programs because we believe that these programs do not fully expand the students" definition of "community." Augustinian pedagogy is based on interaction and 
experiential learning, translating into a requirement of integrated living and teaching by the host country faculty; this precludes study tours, as Augustine held that learning should not be the "passive reception of ideas". Further, the basis of Augustinian educational philosophy is "instruction under hardship" (permolestias eruditio). As much as possible, students are encouraged to leave their comfort zone, hopefully incorporating service-learning and internships. As the Vice President for Academic Affairs wrote in correspondence to one parent:

One of the Augustinian pedagogical principles is the interaction between the Gospel and the world around us. For study abroad, that implies -among many, many other considerations -- an immersion in culture, an interaction with the 'world' that is not Catholic (as well as the world that is, of course), and an openness and sense of inclusivity. It is that Augustinian philosophy of education, dating back the Saint himself, who brought Christianity into dialogue with the world around him that drives our international study strategy and principles. It is, perhaps, a different philosophy than what can be found at other Catholic schools. We would not claim it is necessarily 'better,' but it is, nonetheless, the one we try to promote.

This mission and the many policies surrounding it are made abundantly clear to students, from initial information sessions, individual meetings, an extensive website, a handbook, and the mandatory (online and offline) pre-departure orientation.

\section{Programs available at Villanova University}

There are several programs by which a student can study abroad at Villanova: our "own" semester programs, semester or year-long programs selected by the student, international internships, and summer programs. Academically, a student must have a minimum GPA of 2.75 and must not be on academic probation to participate in the program.

Villanova currently sends students on four of its "own" semester programs, two of which commenced recently in the fall of 2006. In the 2006-2007 academic year, one-fourth of all semester study abroad students were on a Villanova-specific program.

The longest running program is found at NUI, Galway, Ireland. This program is open to all Villanova students and since 2000 two Civil Engineering students have studied there. At NUI, Galway Villanova offers a core course, IS4100 Irish Studies Seminar, taught by the resident director. The class acts as a gateway for students into Irish culture and society and uses the surrounding community as the core reference. Students are required to complete an independent project based on their experience of Irish history and culture. The resident director guides students through these independent projects and evaluates them at the end of the semester for a Villanova grade. Students also enroll in a full-time course load at NUI, Galway and are able to volunteer at various community organizations there to more fully immerse themselves into the Irish environment. With a Villanova faculty member onsite, students facing any academic or other challenges can immediately consult with the resident director to quickly and effectively address the issue. 
Villanova also offers a semester-long study abroad opportunity to second semester freshman business majors. The courses were specifically designed to meet the needs of first year business students and are taught by faculty from local universities. This academic arrangement allows Villanova students to take classes that will advance their business studies and introduce them to the British teaching style. After completing a semester of work, students are placed in an internship that meets their major interests and career goals. These internship experiences are evaluated and students receive Villanova credit upon successful completion of the program.

In fall 2006, Villanova started offering two more overseas semester courses based on the NUI, Galway model. Both of these programs are open to all majors. As they are new, no civil engineering students have participated to date. One program is based in London and focuses on service-learning. The other is in Melbourne and permits students to do field research in an Australian context. Both programs address ideas specific to the particular region and people, and includes close work with foreign faculty members. Students will be evaluated by their overseas faculty and will receive Villanova credit for a successfully completed project. Overseas faculty will be made aware of Villanova's academic expectations and grading philosophy to appropriately award credit.

Villanova students completing internships or field projects abroad face the same stipulations and supervision as those who choose to remain in the United States. Currently, Villanova offers two internship programs for semester students; however, both of these programs are for business students. The first program places second semester freshman business students in London and offers a full business curriculum along with the work experience. The second internship program allows sophomore business students to combine a summer internship in Dublin with a semester of study at NUI, Galway. For all internship placements-including those undertaken through program providers - students are required to complete an academic project based on the work experience (similar to the respective colleges' internship requirements). All internship placements are carefully selected to match the student's interests and level of expertise.

Unlike most universities, Villanova University does not require students to select programs based on an approved list generated by OIS or a faculty committee. Instead, students can choose any program they want as long as it meets four basic criteria: 1. accredited, non-US university affiliation; 2. courses taught by non-US faculty; 3. integrated living arrangements; and 4. nonprofit status. This push towards immersion meant that in the spring of 2007, Villanova University students were in 22 different countries and 71 different universities.

Consequently, for the semester-long programs, most students enroll in non-Villanova programs that have been reviewed for quality of academics and cultural immersion. Therefore, Villanova relies on the program provider or host institution to foster cultural skills while abroad. Prior to departure, the OIS provides students with a general overview of the potential obstacles and challenges they may face. In English-speaking countries, most students are enrolled at a university, while students studying in non-English speaking countries typically attend hybrid programs with the option of studying at a university if their language skill permits. Whenever possible, the OIS encourages students to directly enroll in university courses. The OIS believes 
that direct enrollment options heighten the opportunity for social, cultural, and academic immersion and, therefore, encourages students to take on this challenge whenever possible.

The only exception to criteria \#1, above, is for nontraditional programs where outside-theclassroom learning is built into the program. Typically, these programs include internships, service-learning, or field research. As more and more students study overseas, these programs have become increasingly popular. For instance, in the current academic year, $15 \%$ of students participated in internship programs.

Of equal popularity to the semester programs are the international summer programs. Villanova University oversees 15 summer programs in 11 countries. Summer programs are organized into three different categories: Language and Literature, Business, and Arts and Culture. Engineering students often participate in these programs and use the credit to fulfill their humanities and social science requirements. About half (18) of the Civil Engineers that have gone abroad have participated in this program. Villanova University faculty members coordinate these programs, and non-Villanova students are accepted into the programs. Where possible, the same criteria for semester programs are applied to summer programs, meaning that most programs are university affiliated, hire local faculty for instruction, and have students in integrated living arrangements.

Study abroad and engineering

Open Doors $^{7}$ reported that over 200,000 US students studied abroad in 2004/2005. This was an increase of $8 \%$ over the previous year. Over the past five years engineers have comprised $2.9 \%$ of study abroad students ${ }^{7}$ while they typically comprise about $4.5 \%$ of the undergraduate population $^{8}$.

Several reasons have been postulated for this under-representation of engineers studying abroad: gender balance, inflexibility of curriculum, and inflexibility of the students and faculty9. We will briefly examine each of these reasons. The percentage of women earning Bachelor's degrees in engineering has been around $20 \%$ for the past several years, while the general college population is around $56 \%{ }^{10}$. Women are over-represented in the study abroad population, making up $65 \%$ of those studying abroad ${ }^{6}$. Based on gender alone, one would expect there to be fewer engineers abroad. It is interesting to note that women comprise $70 \%$ of the civil engineering students that have studied abroad at Villanova. Engineering curriculums are typically intensive with a strict pre-requisite structure. In the past, both students and faculty believed that this was an insurmountable block to studying abroad ${ }^{9}$. However, with proper advising and planning, this can easily be overcome. Engineering students are willing to study abroad when the opportunity is available. It is our job as educators to encourage and enable these students so that they may flourish in a more global environment and grow to reach their full potential.

Study abroad and civil engineering at Villanova University

Interaction between OIS and the Civil and Environmental Engineering (CEE) department is crucial to the success of our program. Intensive advising at the departmental level is needed 
because Villanova allows students to choose any university in the world as long as it meets the four basic criteria described earlier. In addition, as with most engineering programs in the US, many of our classes have strict prerequisites, so it is imperative that students plan their overseas study carefully.

As the number of students interested in study abroad increased, the CEE department recognized the importance of advising to the process. In 2003, one faculty member was selected to handle all study abroad cases. This designation of a Study Abroad Adviser has made it easier for students and for OIS because there is only one point of contact. The Study Abroad Adviser is introduced to the students at freshman orientation and again to them as sophomores. The students are encouraged to plan ahead and seek advice as soon as possible. From a curriculum perspective, second semester sophomore year is the ideal time for our students to study abroad; however, it is possible for students to go abroad first semester junior year as well.

Since the class of 2001, 35 civil engineering students have studied abroad either at a university or through a summer program run by Villanova. Civil engineers comprised $37 \%$ of the engineering students that studied abroad in that time period; however, typically civil engineers make up $22 \%$ of each graduating class at Villanova. In addition, the number of students participating in such programs increases every year: in the class of 2001 just one student went abroad as compared to 12 in the class of 2007 (30\% of the class). This indicates that within our college, the civil engineers are eager to study abroad and that they are enabled to act on this desire. We attribute these increasing numbers to several factors: increasing interest in study abroad across the general population of students, appointment of a single point of contact (Study Abroad Adviser), and contact with the students as freshman and sophomores to encourage them to go abroad.

The students that have studied abroad describe their experiences very favorably. For example, when asked if they viewed their experience as a positive one, one student responded:

I was able to visit and live in a different part of the world where I

became adapted to the culture, learned a lot of the history, and took

part in a different learning experience than I was used to at

Villanova. All of these things broadened my perspective in the various areas.

Another student, when asked if this experience helped him grow responded:

It made me grow, and continues to make me grow as a result of changing my insight on things. It opened my eyes to a new reality; different languages, different people, different ways of working, different mindsets... so many new things.

\section{Assessment models}

Most students, administrators, and faculty agree that study abroad has a positive influence on students. However, the assessment of these beliefs is really in its infancy ${ }^{12,13,14,15,16}$. There are several models in existence to assess the success of a study abroad program. Broadly speaking 
these fall into two main categories: academic indicators and self-assessment of growth. The Institute for the International Education of Students Model Assessment Practice (IES MAP) provides a framework for compiling this information into a rigorous assessment process ${ }^{14}$. Academic indicators include grade point average and graduation statistics, such as time to completion of degree. Self-assessments typically probe students' cultural and spiritual growth. In general, schools use the Intercultural Development Inventory (IDI), have developed a tool inhouse $^{16}$, or use both ${ }^{17}$. The major benefit of using the IDI is that is a widely used, robust tool. The major disadvantage of this tool is that is proprietary. This means that one must be trained to administer the instrument and that the institution needs to pay a fee each time the instrument is administered.

The OIS at Villanova is currently in the process of implementing the IES MAP. This is a major effort as the IES MAP focuses on four areas ${ }^{14}$ :

1. Student learning environment

2. Student learning: assessment and intercultural

3. Resources for academic and student support

4. Program administration and development

Full implementation of the IES MAP is likely to be a multi-year process; however, we intend to start assessing our program immediately. To begin with, we have starting tracking and will continue to track academic indicators. Starting in January 2007 we will implement a slightly revised version of the assessment tool developed by Bettez and Lineberry ${ }^{16}$ at the University of Kentucky. The benefit of using Bettez and Lineberry's instrument is two-fold. First, it was developed for engineers and as such contains questions specifically related to ABET outcomes. Second, we will be able to compare our results to those from the University of Kentucky, which should be interesting considering how different our two institutions are.

In addition, we will add several questions about study abroad to our Civil Engineering senior survey starting in the spring of 2007. These questions will ask about the students' perceptions of study abroad and probe why those that did not participate did not pursue overseas study:

1. Were you made aware of study abroad opportunities?

2. Did you study abroad during your time at Villanova?

a. Would you describe the experience as positive? Explain.

b. What type of program did you participate in (summer, semester)?

3. If you did not study abroad, indicate why you did not (for example, you may not have had an interest, your GPA may have been too low to qualify, etc.).

The academic indicators have been studied and these reveal positive results. To date, not one student has had their time at Villanova lengthened because of study abroad; in other words, all study abroad students have graduated on-time. An analysis of grade point averages before and after studying abroad reveals that most students' (67\%) cumulative GPAs are unchanged by studying abroad; $15 \%$ saw a decrease and 19\% saw an increase in GPA after going abroad. A change in GPA was defined as an increase or decrease of more than 0.05. 


\section{Conclusions}

We have seen a dramatic increase in the number of students studying abroad since the class of 2001. Thirty percent of the class of 2007 has had a study abroad experience through either a summer or semester-long program. We have attributed this increase to several factors including more globally aware students and the appointment of a single point of contact for study abroad within the department. As with many programs in the US, we intrinsically believe in the value of study abroad, but we have yet to vigorously assess its impact. This will change as we implement the IES MAP over the next several years, and in the shorter term, an assessment program that includes self-assessment (based on an instrument created by Bettez and Lineberry ${ }^{16}$ and academic indicators (such as grade point average and time to graduation). In addition, by adding questions to our senior survey we will expose the barriers to students taking advantage of this opportunity.

\section{References}

1. ABET (2005), Criteria for Accrediting Engineering Programs, available online at http://www.abet.org/Linked\%20Documents-UPDATE/Criteria\%20and\%20PP/E001\%200607\%20EAC\%20Criteria\%205-25-06-06.pdf.

2. National Academy of Engineering (NAE) (2004) The Engineer of 2020, available online at http://www.nae.edu/nae/engeducom.nsf/weblinks/MCAA-5L3MNK?OpenDocument.

3. Friedman, T.L. (2005) The World is Flat: A Brief History of the $21^{\text {st }}$ Century. Farrar, Straus, and Giroux.

4. Johnson, E., DeMaris, S., Tougaw, D. (2006) "Providing and Integrated International Experiences for Undergraduate Engineering Students at a Small Institution”, Proceedings of the 2006 ASEE Annual Conference, June 18-21, 2006, Chicago, Illinois. Available online at http://www.asee.org/acPapers/code/getPaper.cfm?paperID=11460\&pdf=2006Full2020.pdf.

5. Apple-Smith, J., Miner, S., Riha, A. (2006) "Preparing Engineers for the Global Workplace: Iowa State University", Proceedings of the 2006 ASEE Annual Conference, June 18-21, 2006, Chicago, Illinois. Available online at http://www.asee.org/acPapers/code/getPaper.cfm?paperID=10321\&pdf=2006Full2010.pdf.

6. Open Doors, (2006a), http://opendoors.iienetwork.org/?p=89230.

7. Open Doors (2006b), http://opendoors.iienetwork.org/file_depot/0-10000000/010000/3390/folder/50084/Open+Doors+2006_FastFacts.pdf.

8. National Center for Education Statistics (NCES) (2005), http://nces.ed.gov/programs/digest/d05/tables/dt05_252.asp

9. CIEE Working Party on Science Abroad (2003) Study Abroad for Science and Engineering Students: Barriers to Students and Strategies for Change, available online at http://www.ciee.org/uploads/CIEEScienceandEngineeringReport.pdf.

10. American Society for Engineering Education (ASEE) (2005), http://asee.org/publications/profiles/upload/2005ProfileEng.pdf

11. Gore, J.E. (2005) Dominant Beliefs and Alternate Voices (Discourse, Belief, and Gender in American Study), Routledge.

12. Gillespie, J. (2002) “Colleges Need Better Ways to Assess Study-Abroad Programs”, Chronicle of Higher Education, July 5.

13. DiBiasio, D. and Mello, N.A. (2004) "Multi-Level Assessment of Program Outcomes: Assessing a Nontraditional Study Abroad Program in the Engineering Disciplines", Frontiers: The Interdisciplinary Journal of Study Abroad, Vol 10, pp. 237-252.

14. Institute for International Education of Students (IES) (2003) The IES MAP for Study Abroad, available online at https://www.iesabroad.org/IES/Advisors_and_Faculty/iesMap.html. 
15. DiBiasio, D. (2001) "Outcomes Assessment of an International Engineering Experience", Proceedings of the 2001 ASEE Annual Conference, June 24-27, 2001, Albuquerque, NM. Available online at http://www.asee.org/acPapers/00763_2001.pdf.

16. Bettez, D. and Lineberry, T. (2004) “Assessing Engineering Students' Study Abroad Experiences”, Proceedings of the 2004 ASEE Annual Conference, Salt Lake City, Utah. Available on line at http://www.asee.org/acPapers/2004-13_Final.pdf.

17. Deardorff, D., Comp, D. and Meyer-Lee, E. (2006) "Assessing International Education at Our Institutions: An Overview”, presented at 2006 NAFSA Conference, Montreal, May 21 -26, 2006. Available online at http://www.saintmarys.edu/ cwil/php/intercultural.learning/documents/nafsa2006assessment2.ppt 